\title{
No Citation Advantage for Monograph-Based Collaborations?1
}

\author{
Mike Thelwall*, Pardeep Sud \\ m.thelwall@wlv.ac.uk; p.sud@wlv.ac.uk; Statistical Cybermetrics Research Group, \\ Department of Mathematics and Computer Science, University of Wolverhampton, \\ Wulfruna Street, Wolverhampton WV1 1SB, UK.
}

\begin{abstract}
It is widely believed that collaboration is advantageous in science, for example with collaboratively written articles tending to attract more citations than solo articles, and strong arguments that interdisciplinary collaboration can be particularly powerful. Nevertheless, it is not known whether the same is true for research that produces books. This article tests whether co-authored scholarly monographs attract more citations than solo monographs using books published before 2011 from 30 categories in the Web of Science. The results show that solo monographs numerically dominate collaborative monographs, but give no evidence of a citation advantage for collaboration on monographs. In contrast, for nearly all these subjects (28 out of 30 ) there was a citation advantage for collaboratively produced journal articles. As a result, research managers and funders should not encourage collaborative research in book based subjects or in research that aims to produce monographs, but should allow the researchers themselves to freely decide whether to collaborate or not.
\end{abstract}

Keywords: Collaboration, citation impact, co-authorship, monographs, humanities, social sciences.

\section{Introduction}

Collaboration has long been encouraged by policy makers, research funders and research managers (Katz \& Hicks, 1997) in the belief that it is essential for some types of research, such as Big Science (Price, 1963) or that multi-disciplinary research is essential to solve the problems of the modern world (Gibbons et al., 1994). Perhaps as a result of this, collaboration has increased steadily in academia over the past century, at least in terms of the proportion of scholarly articles that are co-authored (e.g., Moody, 2004; Price, 1963; Wuchty, Jones, \& Uzzi, 2007), with co-authorship particularly prevalent in the hard sciences and quantitative research (e.g., Francescheta \& Costantini, 2010; Lariviere, Gingras, \& Archambault, 2006; Moody, 2004; Wuchty, Jones, \& Uzzi, 2007), and with the recent growth of small research teams (Gazni, Sugimoto, \& Didegah, 2012). Co-authorship is almost ubiquitous in some areas of science, such as Italian medicine (99\%) but much rarer in the social sciences and especially the humanities (Wuchty, Jones, \& Uzzi, 2007), such as $17 \%$ in Italian political and social sciences and $8 \%$ in Italian law (Francescheta \& Costantini, 2010). Indeed, solo monographs seem to be important for academic careers in many areas of the humanities (Cronin, 2012). However, in other areas of human endeavour, such as many arts, co-authored work is rare and individual efforts seem to be essential to most high quality outputs. For example, no book with more than one author has ever been shortlisted for the Man Booker literary prize, and works of art seem to be almost always essentially the work of a single person in the modern era, with some exceptions, such as much performance art,

\footnotetext{
${ }^{1}$ Thelwall, M. \& Sud, P. (in press). No citation advantage for monograph-based collaborations? Journal of Informetrics.
} 
some postmodern art (Green, 2001; cited in Cronin, 2012), and many modern pop music compositions. Hence it is important to not assume that teamwork is always superior and to identify areas or types of scholarship, if any, for which collaboration should not be encouraged.

Previous research has investigated collaboration mainly in terms of the citation impact of academic articles, broadly showing that co-authored articles tend to be more highly cited than single authored articles across the sciences and in some social sciences, but there seems to be no evidence about this in the arts and humanities. In contrast, some have argued that collaboratively produced research in some areas of the humanities is not valued (Ede \& Lunsford, 2001), which can impact on the reputations of scholars producing it. No previous research has focused on the citation impact of collaboration for monographs, however, which are the core outputs of scholarship in the humanities and some social sciences (Nederhof, 2006), and hence should shed the most light on the importance of collaboration and individual work in the humanities. Although there have been claims that book publishing is declining in the humanities (Thompson, 2007), at least one empirical study has contradicted this (Engels, Ossenblok, \& Spruyt, 2012).

This article assesses the effect of collaboration on the impact of scholarly monographs, focusing particularly on the humanities and using citation counts as impact indicators to assess whether collaboratively-produced monographs tend to have a higher citation impact than solo monographs. This is assessed using citations to books indexed in the Thomson Reuters Book Citation Index $(\mathrm{BKCl})$, analysed separately for each of the 30 subject areas with the most books.

\section{Literature Review}

Although collaboration in science seems to be a historical product of the professionalization of research (deB Beaver \& Rosen, 1978), at one level, almost all academic products are collaborative to some extent. In addition to indirect collaboration in the sense of building upon, learning from, or being influenced by the work of others, research may have inputs from informal discussions, referees and editors. Such things are sometimes recorded in acknowledgements, and can be thought of as sub-authorship (Cronin, Shaw, \& La Barre, 2003). Although cooperation between scholars can occur in many forms, perhaps the most transparent form is that which results in the co-authorship of publications, the focus here. Whilst co-authorship does not always indicate a direct contribution in some fields (Cronin, 2001), in particular with honorary co-authorships apparently common in medicine and particle physics, in most disciplines it seems to be a reasonable way of identifying the people that have made direct and substantial contributions to a publication.

There are many different types of academic collaboration. For example, in addition to two or more authors collaborating on all stages of a process, an author may help the main author by supervising their work, completing a specific task within a project (e.g., literature review, building an instrument, data collection or analysis), or by providing comments or advice on a key aspect (Katz \& Martin, 1997; Sonnenwald, 2007).

\subsection{The citation impact of collaboration}

Co-authorship has been shown to associate with higher citation impact in many cases. For example the average citation impact of all Science Citation Index (SCl) articles increased approximately linearly with the number of authors in 1998, with the impact of international collaboration increasing more than that of domestic collaboration (Persson, Glänzel, \& 
Danell, 2004). Similarly, a moderate positive correlation was found between the number of authors and the number of citations for 11,196 South African $\mathrm{SCl}$ (expanded) articles and reviews from 2000, 2003 and 2005 (Sooryamoorthy, 2009), and an association between the number of authors and citation rates was found for most areas of Italian science 2000-2003 (Francescheta \& Costantini, 2010). Within science, an increased citation impact for collaborative articles has been shown for biomedical research, chemistry and mathematics (Glänzel, 2002), for Spanish authors in three Biomedical subfields (Bordons, Gomez, Fernandez, Zulueta, \& Mendez, 1996), for Chinese molecular biology with international collaboration (Ma \& Guan, 2005), (a minor effect) for an ecology journal 1998-2000 (Leimu \& Koricheva, 2005), and for biology, biochemistry and chemistry 2000-2009 (Didegah \& Thelwall, 2013). In contrast, no relationship was found between citation impact and the number of authors for 2000 published short articles submitted to a single chemistry journal (Bornmann, Schier, Marx, \& Daniel, 2012), and Italian physics articles 2000-2003 with large numbers of authors were less cited than Italian physics articles with few authors (Francescheta \& Costantini, 2010).

The social sciences are areas of scholarship relating to society and typically using empirical methods. Across the social sciences 2000-2009, articles with more authors tended to have more citations (Didegah \& Thelwall, 2013). Within library and information science articles the proportion of the most highly cited articles that were collaborative increased steadily 1976-2004 (Levitt \& Thelwall, 2009), Brazilian management science articles 19811995 (but only $n=66$ ) had a higher impact if they were internationally collaborative (Pereira, Fischer, \& Escuder, 2000), collaborative economics articles were more highly cited than solo articles in most countries and most US states but the apparent strength of the advantage depends on the indicator used (Levitt, \& Thelwall, 2010), co-authorship significantly associated with higher citation counts in management and organizational studies (Acedo, Barroso, Casanueva, \& Galán, 2006), and Italian economics and statistics collaborative articles 2000-2003 were more highly cited (Francescheta \& Costantini, 2010). In contrast, the collaborative articles of the 30 most highly cited information scientists 1976-2004 were not significantly more highly cited than their solo articles (Levitt \& Thelwall, 2009), coauthored articles in 14 finance journals 1987-1991 $(n=540)$ were not significantly more highly cited than solo articles (Avkiran, 1997), and 308 articles from three social personality journals in 1998 were not significantly more highly cited if collaborative (Haslam et al., 2008).

The humanities are areas of scholarship that focus on human culture and which typically use critical argument rather than empirical methods. Within the humanities there are relatively few findings about the impact or value of co-authorship, perhaps because it is rare. No significant association was found between co-authorship and citation counts for 2000-2003 Italian publications in three areas: philological-literary sciences, antiquities and arts; history, philosophy, psychology, and pedagogy (the latter two social sciences were analysed alongside the former two humanities); and law (Francescheta \& Costantini, 2010).

Although there are many reasons why collaboration might produce better scientific research (e.g., Gibbons et al., 1994; Katz \& Hicks, 1997), an extraneous reason why collaborative research may be more highly cited is that there are more authors to self-cite and so, assuming a degree of self-citation, co-authored works should tend to be more cited, irrespective of quality (Van Raan, 1998). Another possibility is that quantitative research is more likely to be both collaborative and highly cited, creating a spurious association between citation counts and collaboration. In response, one study has used a national 
research assessment exercise to relate collaboration with peer review ratings on a large scale. For Italian research 2000-2003, in most (11 out of 14) areas of scholarship, highly collaborative articles were significantly more likely to be judged to be of high quality than were others (Francescheta \& Costantini, 2010). The exceptions were law, mathematics and computer sciences, and civil engineering and architecture. This suggests that co-authored research may tend to be higher quality in general but not necessarily in all disciplines. In particular, within the humanities average peer ratings tend to be higher for publications with more authors in both philological-literary sciences, antiquities and arts (PAA), and history, philosophy, psychology and pedagogy (Francescheta \& Costantini, 2010).

\subsection{Types of collaboration}

Many studies have shown that different types of collaboration have different apparent effects on citation impact. One common finding is that international collaboration is the most likely type to be associated with more citations (Katz \& Martin, 1997) and that interinstitutional collaboration is the least likely to associate with higher citation counts. For example, international collaboration associates with higher citations than does national collaboration for European biotechnology and applied microbiology 1988-2002 (Frenken, Hölzl, \& de Vor, 2005), and international rather than national collaboration associates with higher citations in biology, biochemistry and chemistry, but not in the social sciences (Didegah \& Thelwall, 2013). In contrast, internationalism had no significant association with citation counts for articles in an ecology journal 1998-2000, but intra-institutional collaboration associated with lower citation counts (Leimu \& Koricheva, 2005).

\subsection{Books}

No previous studies seem to have evaluated the citation impact of books from the perspective of collaboration. Nevertheless, a study of monographs and edited volumes published by Malaysian university presses found co-authored books disproportionately prevalent amongst the highest cited (Abdullah \& Thelwall, in press). A study of book chapters in $\mathrm{BKCl}$ mapped their citation patterns by publisher but did not investigate collaboration (Torres-Salinas, Rodriguez-Sánchez, Robinson-Garcia, Fdez-Valdivia, \& García, 2013).

\section{Research Questions}

The objective of this article is to assess whether collaboration tends to produce higher quality scholarly monographs. Citation counts are used as the key indicator for the comparison. Although peer review would probably be superior to citation counts as an indicator of the quality or impact of books, gathering peer review scores for large collections of books is impractical, so citation counts are a reasonable choice for a large-scale analysis. This article addresses the following main research questions.

- Does the citation impact of academic monographs differ according to whether they are produced collaboratively or individually?

- Does the citation impact of collaboration differ between academic monographs and articles within the same subject area? 


\section{Data and Methods}

Citations to a large collection of academic books were needed to answer the research questions. Books indexed in $\mathrm{BKCl}$ were used as these have the necessary citation counts and are sufficiently numerous for a large study. In contrast, Scopus began adding books on a large scale only in 2013, too recent to attract enough citations. It would also have been possible to use Google Books for citation data (Kousha \& Thelwall, 2009) but this has the disadvantage that search-based heuristics are needed to identify citations to books and the accuracy of these may be affected by the number of authors that a book has, so the method for counting citations is not optimal for comparing collaborative to solo books. Library holdings are another potential alternative metric of monograph success (Linmans, 2010; White et al., 2009) but these do not seem to be clearly superior to citations.

Although citation counts are widely used as indicators of the impact of academic research, their use is often controversial and seems to be most accepted in the physical sciences and medicine. For example, in the UK Research Excellence Framework 2014, citations were used in only 11 out of 36 subject areas ${ }^{2}$, excluding all arts and humanities and with Economics and Econometrics being the only social science area using citations. Citations are least accepted in the arts and humanities, perhaps because neither area relies upon traditional journal articles. Moreover, citations are used differently in the humanities, and are not typically used to acknowledge the contribution of prior research (Hellqvist, 2010). In addition, part of the impact of humanities research is on the public rather than other researchers, and citation counts could not capture this aspect of impact (Hellqvist, 2010). Nevertheless, whilst it could be unfair to use citations to evaluate individual humanities scholars or individual books, it still seems likely that higher regarded books would tend to be more cited, even if there are many individual exceptions, and even if there is not a direct cause-and-effect relationship in terms of book citations acknowledging the contributions of previous works.

Books are categorised into one or more subject categories in $\mathrm{BKCl}$, and because the advantage of collaboration may vary by field, books were analysed by subject category. In addition, edited volumes are different types of book to monographs, so only monographs were analysed. For each of the 30 largest subject areas in terms of total books, $\mathrm{BKCl}$ citation counts were obtained for all books in the subject category that were written in English, not edited works, not dual classified (e.g., as a book and an article), and not anonymous. Hence the sample consists of English language monographs with named authors. Books are sometimes classified into multiple subject categories and all books in a category were examined irrespective of whether they were also in other categories. All citations in the Web of Science (WoS) were included (Science Citation Index Expanded, Social Sciences Citation Index, Arts \& Humanities Citation Index, Conference Proceedings Citation Index Science, Conference Proceedings Citation Index - Social Science \& Humanities, Book Citation Index - Science, Book Citation Index - Social Science), not just citations from other books. The data was downloaded on October 6, 2013 by searching in WoS for documents of type "Book", refining the results by a given subject area and refining to exclude non-books (books also classified as something else). After downloading the data, all books without an author listed in WoS or with the author listed as anonymous were removed. Books without an author appeared to be edited works, since all had entries listed in the Book Editors field. Under $1 \%$ of the books with a listed author also had a listed editor (e.g., $0.9 \%$ in Education,

\footnotetext{
${ }^{2}$ http://www.ref.ac.uk/subguide/citationdata/
} 
$0.2 \%$ in Religion), and these were retained. For example, The Monstrosity of Christ: Paradox or Dialectic? has Zizek and Milbank as authors and Davis as editor - it is a dialog between the two authors edited by Davis. Some of these were data entry errors since an author was listed as an editor or vice-versa (e.g., BioMath in the Schools had Cozzens listed as an editor and Roberts as an author, but both were editors) but the low numbers means that such errors are unlikely to affect the results, especially if the errors are random, which seems likely.

The number of citations to each monograph was taken from the Times Cited WoS field. These citations are to the entire book and do not include citations to individual chapters within each book. It has been argued that a fair treatment of citations to books should normalise for the number of chapters in a book so that longer works do not have an advantage for additional chapters (Gorraiz, Purnell, \& Glänzel, 2013; Leydesdorff \& Felt, 2012). This logic makes sense for edited volumes but perhaps less for monographs because these are single coherent pieces of work rather than edited collections, and because citations to monograph chapters are rare (Gorraiz, Purnell, \& Glänzel, 2013). In theory, citations to books could be normalised by the number of chapters (not in WoS), number of pages (in WoS) or number of words (not in WoS). However, testing suggested that there was no relationship between monograph length and the number of authors, so size normalisation was not necessary for differentiating between the impacts of solo and multiauthored monographs (i.e., not normalising for size would not advantage solo or multiauthored monographs). For example, the Spearman correlation between the number of authors of Education monographs and the number of pages in the monographs was 0.005, which is not statistically significant $(p=0.867)$, and for Management monographs, the Spearman correlation was in the opposite direction $(-0.038)$ and also not significant $(p=0.427)$. There was a statistically significant relationship between monograph length and number of authors in some categories, but this seemed too small to be meaningful (e.g., the length difference was $7.5 \%$ between solo and co-authored History monographs). Longer monographs did seem to attract slightly more citations, however (e.g., the Spearman correlation between citations and pages for Management monographs was 0.163 , with $p=0.001$ ), so size may be a factor in future studies where the independent variable associates with size.

Mann-Whitney $U$ tests were used to check for significant differences between the citations received by single author books and citations received by books with at least two authors. Since most books had just one author, books by more than one author were combined into a single category rather than analysed separately by number of authors. A more fine grained analysis for different numbers of authors or countries in collaborative papers was not attempted due to the small number of collaborative monographs included (Francescheta \& Costantini, 2010). The Mann-Whitney test is suitable for skewed data, such as citation counts, and detects if the values in one data set tend to be larger than the values in another.

Recent books are unlikely to be cited and their inclusion in a test can dilute the data and weaken the power of the test. Experiments with the largest categories suggested that the most powerful test would be for books published in or before 2010 (e.g., if using all books up to 2013 then only three of the p-values in Table 1 would have been below 0.05) so this cut-off date was used in order to maximise the power of the tests. Almost all books were published in or after 2003, giving a total of 8 years' of books, with between 10 years, 9 months and 2 years, 9 months for each book to attract citations. A Bonferroni correction 
was used for $n=30$ to compensate for the increased probability of a false positive from 30 tests, changing the $p=0.05$ significance value to $p=0.0017$. Ranking change percentages were estimated by dividing the difference of the average ranks between collaborative and solo monographs by the range of ranks (the number of publications, subtract 1 ). This indicator gives a measure, within each subject category, of the difference in rank between the average collaborative monograph and the average solo monograph.

To assess whether the results were due to the subjects analysed or to the medium analysed, the citation impact of the non-anonymous English articles in WoS published in 2006, the approximate midpoint of 2002-2010 (although before the median of 2008), was analysed for the effect of collaboration for the same 30 subject categories. For large categories, only 2,500 articles from the year were sampled and anonymous articles were removed in all cases. As with books, articles in each subject category were examined irrespective of whether they were also classified in other subject categories.

\section{Results}

Table 1 reports the results of the 30 Mann-Whitney tests, none of which were positive. The lack of a positive result is remarkable given the large sample sizes involved, so if collaboration is a factor in citations for books, then its influence is likely to be only minor. The last column of Table 1 shows that in 17 subject areas multi-authored works tended to attract more citations than solo works, and in 12 subject areas the opposite was true. Overall, the average multi-authored book is ranked $0.03 \%$ higher than the average solo book. These figures confirm that collaboration is not an important factor for citation impact in the production of a monograph, at least in the major subject areas covered by $\mathrm{BKCl}$. To confirm that taking monograph length into account would not affect the results enough to change the conclusions, the tests for the six lowest $p$ values were repeated with citations per page as the dependant variable (giving History, $p=0.037$, Political Science $p=0.012$, Education $p=0.012$, Sociology $p=0.067$, Engineering Electrical Electronic $p=0.038$, Communication $\mathrm{p}=0.076)$, giving no new significant results. 
Table 1.Man-Whitney tests for differences in citations between solo and multi-authored monographs. Books are taken from BKCl, published in English before 2011, not edited works and not dual classified as anything other than a book in $\mathrm{BKCl}$. The Rank adv. multi. column indicates the average ranking increase for a multi-authored book in comparison to a singleauthored book.

\begin{tabular}{|c|c|c|c|c|c|c|}
\hline Name & Books & $\begin{array}{l}\text { Single } \\
\text { auth. (\%) }\end{array}$ & $\begin{array}{l}\text { Auth. } \\
\text { diff. } p^{*}\end{array}$ & $\begin{array}{l}\text { Single } \\
\text { av. } \\
\text { rank }\end{array}$ & $\begin{array}{l}\text { Multi } \\
\text { av. } \\
\text { rank }\end{array}$ & $\begin{array}{l}\text { Rank } \\
\text { adv. } \\
\text { multi. }\end{array}$ \\
\hline History & 2043 & $95 \%$ & 0.015 & 1029 & 885 & $-7 \%$ \\
\hline Political Science & 2045 & $87 \%$ & 0.019 & 1011 & 1101 & $4 \%$ \\
\hline Economics & 1218 & $72 \%$ & 0.072 & 598 & 639 & $3 \%$ \\
\hline Literary Theory Criticism & 1123 & $97 \%$ & 0.461 & 561 & 603 & $4 \%$ \\
\hline International Relations & 871 & $84 \%$ & 0.368 & 439 & 418 & $-2 \%$ \\
\hline Religion & 836 & $95 \%$ & 0.934 & 418 & 421 & $0 \%$ \\
\hline Philosophy & 694 & $94 \%$ & 0.493 & 349 & 327 & $-3 \%$ \\
\hline Law & 668 & $86 \%$ & 0.531 & 336 & 323 & $-2 \%$ \\
\hline Education Educational Research & 654 & $69 \%$ & 0.018 & 316 & 353 & $6 \%$ \\
\hline Sociology & 648 & $84 \%$ & 0.032 & 318 & 360 & $6 \%$ \\
\hline Mathematics Applied & 552 & $52 \%$ & 0.078 & 265 & 289 & $4 \%$ \\
\hline Literature & 526 & $95 \%$ & 0.686 & 263 & 275 & $2 \%$ \\
\hline Business & 490 & $69 \%$ & 0.174 & 240 & 258 & $4 \%$ \\
\hline Language Linguistics & 470 & $86 \%$ & 0.106 & 231 & 261 & $6 \%$ \\
\hline Management & 439 & $63 \%$ & 0.849 & 219 & 221 & $0 \%$ \\
\hline Engineering Electrical Electronic & 431 & $44 \%$ & 0.014 & 232 & 203 & $-7 \%$ \\
\hline Mathematics & 466 & $58 \%$ & 0.068 & 224 & 246 & $5 \%$ \\
\hline History Philosophy of Science & 380 & $86 \%$ & 0.649 & 192 & 184 & $-2 \%$ \\
\hline Women's Studies & 363 & $90 \%$ & 0.431 & 183 & 169 & $-4 \%$ \\
\hline Linguistics & 358 & $82 \%$ & 0.095 & 175 & 199 & $7 \%$ \\
\hline Business Finance & 326 & $65 \%$ & 0.431 & 166 & 158 & $-2 \%$ \\
\hline Ethnic Studies & 317 & $93 \%$ & 0.327 & 158 & 177 & $6 \%$ \\
\hline Computer Science Theory Methods & 291 & $52 \%$ & 0.167 & 140 & 153 & $4 \%$ \\
\hline Planning Development & 280 & $54 \%$ & 0.809 & 142 & 139 & $-1 \%$ \\
\hline Social Sciences Interdisciplinary & 271 & $85 \%$ & 0.721 & 137 & 132 & $-2 \%$ \\
\hline Communication & 262 & $79 \%$ & 0.048 & 127 & 149 & $8 \%$ \\
\hline Environmental Studies & 254 & $69 \%$ & 0.097 & 133 & 116 & $-7 \%$ \\
\hline Computer Science Artificial Intelligence & 224 & $45 \%$ & 0.939 & 113 & 112 & $0 \%$ \\
\hline Environmental Sciences & 170 & $58 \%$ & 0.210 & 82 & 91 & $5 \%$ \\
\hline Biochemistry Molecular Biology & 67 & $60 \%$ & 0.907 & 34 & 34 & $0 \%$ \\
\hline
\end{tabular}

${ }^{*}$ A p value below 0.0017 is needed for a significant result (Bonferroni corrected).

In contrast to the case for books, the results suggest a citation advantage for collaborative academic articles in all subjects except Literary Theory Criticism and Ethnic Studies. The increased number of significant results is at least partly due to the larger sample size involved and the longer effective time window, since most of the monographs were published later and books need longer to attract citations anyway. Nevertheless, the overall ranking increase estimate of $16 \%$ for collaborative vs. solo articles (averaged per article in 
Table 2, hence underestimating for subjects in which not all articles were sampled) is clear evidence that for the same subject areas, whilst collaboration tends to have no association with citation counts for monographs, collaboration does tend to associate with higher citation counts for articles. One of the most striking subjects is History: historians could expect an average $7 \%$ citation rank decrease for collaborating on books but a $9 \%$ increase for collaborating on articles.

Table 2: Man-Whitney tests for differences in citations between solo and multi-authored articles published in English in 2006. The Rank adv. multi. column indicates the average ranking increase for a multi-authored article in comparison to a single-authored article.

\begin{tabular}{|c|c|c|c|c|c|c|}
\hline Name & $\begin{array}{l}\text { Article } \\
\text { sample }\end{array}$ & $\begin{array}{l}\text { Single } \\
\text { auth. (\%) }\end{array}$ & $\begin{array}{l}\text { Auth. } \\
\text { diff. } p\end{array}$ & $\begin{array}{l}\text { Single } \\
\text { av. } \\
\text { rank }\end{array}$ & $\begin{array}{l}\text { Multi } \\
\text { av. } \\
\text { rank }\end{array}$ & $\begin{array}{l}\text { Rank } \\
\text { adv. } \\
\text { multi. }\end{array}$ \\
\hline History & 2080 & $93 \%$ & $0.000 *$ & 1027 & 1219 & $9 \%$ \\
\hline Political Science & 2431 & $70 \%$ & $0.000 *$ & 1072 & 1550 & $20 \%$ \\
\hline Economics & 2498 & $37 \%$ & $0.000 *$ & 1079 & 1351 & $11 \%$ \\
\hline Literary Theory Criticism & 248 & $98 \%$ & 0.331 & 125 & 101 & $-10 \%$ \\
\hline International Relations & 1376 & $47 \%$ & $0.000 *$ & 600 & 769 & $12 \%$ \\
\hline Religion & 1196 & $91 \%$ & $0.000 *$ & 579 & 804 & $19 \%$ \\
\hline Philosophy & 1888 & $93 \%$ & $0.000 *$ & 923 & 1240 & $17 \%$ \\
\hline Law & 2279 & $77 \%$ & $0.000 *$ & 1053 & 1426 & $16 \%$ \\
\hline Education Educational Research & 2485 & $48 \%$ & $0.000 *$ & 1132 & 1344 & $9 \%$ \\
\hline Sociology & 2128 & $56 \%$ & $0.000 *$ & 940 & 1222 & $13 \%$ \\
\hline Mathematics Applied & 2500 & $29 \%$ & $0.000 *$ & 1101 & 1312 & $8 \%$ \\
\hline Literature & 2122 & $97 \%$ & $0.000 *$ & 1051 & 1349 & $14 \%$ \\
\hline Business & 2481 & $29 \%$ & $0.000 *$ & 938 & 1367 & $17 \%$ \\
\hline Language Linguistics & 979 & $82 \%$ & $0.000 *$ & 449 & 676 & $23 \%$ \\
\hline Management & 2496 & $24 \%$ & $0.000 *$ & 1066 & 1307 & $10 \%$ \\
\hline Engineering Electrical Electronic & 2489 & $11 \%$ & $0.000 *$ & 858 & 1294 & $18 \%$ \\
\hline Mathematics & 2499 & $42 \%$ & $0.000 *$ & 1113 & 1351 & $10 \%$ \\
\hline History Philosophy of Science & 426 & $79 \%$ & $0.000 *$ & 202 & 257 & $13 \%$ \\
\hline Women's Studies & 437 & $72 \%$ & $0.000 *$ & 200 & 268 & $16 \%$ \\
\hline Linguistics & 1346 & $52 \%$ & $0.000 *$ & 559 & 796 & $18 \%$ \\
\hline Business Finance & 2186 & $43 \%$ & $0.000 *$ & 732 & 1363 & $29 \%$ \\
\hline Ethnic Studies & 239 & $79 \%$ & 0.036 & 115 & 138 & $10 \%$ \\
\hline Computer Science Theory Methods & 2500 & $23 \%$ & $0.000 *$ & 564 & 1936 & $55 \%$ \\
\hline Planning Development & 1376 & $47 \%$ & $0.000 *$ & 600 & 769 & $12 \%$ \\
\hline Social Sciences Interdisciplinary & 1705 & $56 \%$ & $0.000 *$ & 716 & 1025 & $18 \%$ \\
\hline Communication & 1261 & $38 \%$ & $0.000 *$ & 555 & 678 & $10 \%$ \\
\hline Environmental Studies & 2360 & $36 \%$ & $0.000 *$ & 982 & 1294 & $13 \%$ \\
\hline Computer Science Artificial Intelligence & 2499 & $13 \%$ & $0.000 *$ & 1066 & 1278 & $8 \%$ \\
\hline Environmental Sciences & 2498 & $6 \%$ & $0.000 *$ & 990 & 1267 & $11 \%$ \\
\hline Biochemistry Molecular Biology & 2498 & $2 \%$ & $0.000 *$ & 761 & 1258 & $20 \%$ \\
\hline
\end{tabular}

${ }^{*} p$ value below 0.0017 indicating a significant result (Bonferroni corrected). 


\section{Discussion and limitations}

An important limitation is the data source. $\mathrm{BKCl}$ books are selected by a panel organised by Thomson Reuters, presumably in an attempt to include those that are most useful to academics. BKCl takes its books predominantly from commercial publishers, its edited books tend to be more cited than its monographs and books that are included in series tend to be more cited (Torres-Salinas, Robinson-Garcia, Cabezas-Clavijo, \& Jiménez-Contreras, 2013). Presumably the number of authors for a book was not a factor in the selection of books and so it is reasonable to regard the $\mathrm{BKCl}$ collection as relatively unbiased from the perspective of collaboration. Nevertheless, $\mathrm{BKCl}$ only includes books in a few languages and is dominated by English texts and so there may be secondary biases, especially if collaboration practices differ between countries. This is especially important because the humanities tend to me more regionally organised than sciences (Nederhof, 2006). The method used to identify monographs (selecting documents classified as books and not dual classified as anything else, and removing books that did not have registered authors whilst retaining a small number of books with both editors and authors) is also a limitation because some of these records may be for other types of documents than traditional monographs, but classified as books for convenience, such as the Zizek and Milbank dialog mentioned above, but perhaps also theses and reports.

A limitation in the interpretation of the results is that collaboration is equated with authorship whereas authorship attribution practices vary, from honorary authorships in some areas of science to the work of individual artists being attributed to more senior artists in others (Cronin, 2012). Hence it is not clear whether solo monographs in fact include a substantial degree of collaboration, for example in discussions of ideas with colleagues or with helpers conducting literature searches or even writing or editing preliminary versions of chapters (e.g., We think: Mass innovation, not mass production by Charles Leadbeater was placed online for anyone to edit). Similarly, collaborative monographs might also occasionally include honorary authorships.

The use of citations to evaluate the impact of monographs is also a limitation because such citations can only partially reflect the goals of humanities research (Hellqvist, 2010), so it remains possible, for example, that collaborative monographs in the humanities have higher (or lower) impact than monographs outside academia. The citation window length was also relatively short for books and hence a similar study carried out in a few years with a longer citation window may well find some significant results, although it seems likely that any citation advantage found will not be substantial.

The largest subject category, History, was examined in more detail for insights into collaborative practices. There was no significant difference between co-authored and solo monographs in terms of publication year (Mann-Whitney, $p=0.117$ ), so it is not likely that a citation advantage for collaborative or solo monographs could have been hidden by one or the other tending to have been published earlier. Collaborative monographs tended to be shorter (Mann-Whitney, $\mathrm{p}=0.001$ ) than were solo monographs but the difference seems too small to be relevant (median 259 rather than 280, a difference of 7.5\%). Collaborative monographs tended to have been included in more subject categories than had solo monographs (Mann-Whitney, $p=0.001$ ), although the difference is again small (means 1.55 and 1.72, respectively). This suggests a slight tendency for collaborative monographs to be more interdisciplinary, presumably with multiple authors combining different disciplinary perspectives. Monographs with more subject categories tended to be more highly cited (Mann-Whitney, $p=0.001$ ), suggesting a citation advantage for interdisciplinary research. 
Combining these last two findings, it is perhaps surprising that collaborative history monographs were not more highly cited than solo history monographs. It also suggests, by default, that solo work may be more advantageous for "pure" history monographs. The most highly cited collaborative monographs for the largest subject category, history, were examined to check whether there was something unusual about them that could explain the results. Within the 100 most cited history books, 5 were collaborative. All seemed to be standard history monographs with no unusual features and all had two authors: Central Africans, Atlantic Creoles, and the Foundation of the Americas, 1585-1660; Power and Plenty: Trade, War, and the World Economy in the Second Millennium; Creating Abundance: Biological Innovation and American Agricultural Development; Reversible Destiny: Mafia, Antimafia, and the Struggle for Palermo; American Environmental Policy, 1990-2006: Beyond Gridlock.

Although the results give no evidence of a collaboration advantage or disadvantage for monographs in any subject, there may be some collaboration advantages or disadvantages that were not large enough to trigger a positive result in the tests due to the small numbers of books involved for some subjects. Nevertheless, the largest advantage for any subject area was only $8 \%$, which is still relatively minor and arguably too minor to be a factor for authors to consider when deciding whether to collaborate or not.

The difference between the lack of a citation advantage for collaboration on monographs (not significant in any category and only $0.03 \%$ overall) and the clear citation advantage for collaboration on articles in the same subjects (significant in most categories and $16 \%$ overall, although both figures benefit from a longer citation window for articles) suggests that, in general, the output format is more important than the subject area for collaboration. Presumably the key factor here is length: the advantages of collaboration for short publications disappear for the much longer monographs. Hence, in any subject area, work leading to the production of a book should not be assumed to need collaboration. In contrast, there is a possibility that work in most subject areas leading to the production of an academic article could get a citation advantage from collaboration.

\section{Conclusions}

The results suggest that collaboration is not important for the production of high quality scholarly monographs in any subject area, even though it associates with higher citation counts for research published in articles in most subject areas. Hence, whilst it is reasonable for funders and research managers to encourage collaboration in science in order to produce higher quality research, they should be careful to avoid this for research that produces monographs. Since books are particularly important in the humanities, this suggests that collaboration should not be promoted in the humanities by research funders or managers. Nevertheless, the data also does not support those that claim that collaboration is detrimental to humanities research and so collaboration should not be actively discouraged either. Instead, it seems that humanities authors should be allowed to make the final decision for each of their projects and collaborate if they believe that it will be useful for their research without any incentives one way or another (this echoes Sonnenwald, 2007). In the current environment of apparently intensive competition for funding, applicants might otherwise commit themselves to non-optimal collaboration strategies in order to have the best chance of being successful in funding applications.

For future research, it would be interesting to investigate book chapters to see if the role of collaboration in them is more similar to monographs or to articles. It is also 
important to assess different collections of books to check whether the results reported here may be influenced by the selection criteria used for $\mathrm{BKCl}$. Finally, since the humanities are quite regionally organised, it would be useful to carry out studies for countries or languages with substantial monograph production to see whether the patterns found here apply to humanities research in general.

\section{References}

Abdullah, A., \& Thelwall, M. (in press). Can the impact of non-western academic books be measured? An investigation of Google books and Google scholar for Malaysia. Journal of the American Society for Information Science and Technology,

Acedo, F., Barroso, C., Casanueva, C., \& Galán, J. (2006). Co-authorship in management and organizational studies: An empirical and network analysis. Journal of Management Studies, 43(5), 957-983. doi:10.1111/j.1467-6486.2006.00625.x

Avkiran, N. K. (1997). Scientific collaboration in finance does not lead to better quality research. Scientometrics, 39(2), 173-184.

Bordons, M., Gomez, I., Fernandez, M. T., Zulueta, M. A., \& Mendez, A. (1996). Local, domestic and international scientific collaboration in biomedical research. Scientometrics, 37(2), 279-295.

Bornmann, L., Schier, H., Marx, W., \& Daniel, H. (2012). What factors determine citation counts of publications in chemistry besides their quality? Journal of Informetrics, 6(1), 11-18.

Cronin, B. (2001). Hyperauthorship: A postmodern perversion or evidence of a structural shift in scholarly communication practices? Journal of the American Society for Information Science and Technology, 52(7), 558-569. doi:10.1002/asi.1097

Cronin, B. (2012). Collaboration in art and science: Approaches to attribution, authorship and acknowledgment. Information \& Culture, 47(1), 18-37.

Cronin, B., Shaw, D., \& La Barre, K. (2003). A cast of thousands: Coauthorship and subauthorship collaboration in the 20th century as manifested in the scholarly journal literature of psychology and philosophy. Journal of the American Society for Information Science and Technology, 54(9), 855-871.

deB Beaver, D., \& Rosen, R. (1978). Studies in scientific collaboration part I. The professional origins of scientific co-authorship. Scientometrics, 1(1), 65-84.

Didegah, F., \& Thelwall, M. (2013). Which factors help authors produce the highest impact research? Collaboration, journal and document properties. Journal of Informetrics, 7(4), 861-873.

Ede, L., \& Lunsford, A. (2001). Collaboration and concepts of authorship. Pmla, 116(2), 354369.

Engels, T. C. E., Ossenblok, T. L. B., \& Spruyt, E. H. J. (2012). Changing publication patterns in the social sciences and humanities, 2000-2009. Scientometrics, 93(2), 373-390.

Francescheta, M., \& Costantini, A. (2010). The effect of scholar collaboration on impact and quality of academic papers. Journal of Informetrics, 4(4), 540-553.

Frenken, K., Hölzl, W., \& de Vor, F. (2005). The citation impact of research collaborations: The case of European biotechnology and applied microbiology (1988-2002). Journal of Engineering and Technology Management, 22(1), 9-30.

Gazni, A., Sugimoto, C. R., \& Didegah, F. (2012). Mapping world scientific collaboration: Authors, institutions, and countries. Journal of the American Society for Information Science \& Technology, 63(2), 323-335. 
Gibbons, M., Limoges, C., Nowotny, H., Schwartzman, S., Scott, P., \& Trow, M. (1994). The new production of knowledge. London, UK: Sage.

Glänzel, W. (2002). Coauthorship patterns and trends in the sciences (1980-1998): A bibliometric study with implications for database indexing and search strategies. Library Trends, 50(3), 461-473.

Gorraiz, J., Purnell, P.J., \& Glänzel, W. (2013). Opportunities for and limitations of the Book Citation Index. Journal of the American Society for Information Science and Technology, 64(7), 1388-1398.

Green, C. (2001). The third hand: Collaboration in art from conceptualism to postmodernism. Minneapolis, MN: University of Minnesota Press.

Haslam, N., Ban, L., Kaufmann, L., Loughnan, S., Peters, L., Whelan, S., \& Wilson, A. (2008). What makes an article influential? Predicting impact in social and personality psychology. Scientometrics, 76(1), 169-185.

Hellqvist, B. (2010). Referencing in the humanities and its implications for citation analysis. Journal of the American Society for Information Science and Technology, 61(2), 310-318.

Katz, J. S., \& Hicks, D. (1997). How much is a collaboration worth? A calibrated bibliometric model. Scientometrics, 40(3), 451-554.

Katz, J. S., \& Martin, B. R. (1997). What is research collaboration? Research Policy, 26(1), 118.

Kousha, K., \& Thelwall, M. (2009). Google book search: Citation analysis for social science and the humanities. Journal of the American Society for Information Science and Technology, 60(8), 1537-1549.

Lariviere, V., Gingras, Y., \& Archambault, É. (2006). Canadian collaboration networks: A comparative analysis of the natural sciences, social sciences and the humanities. Scientometrics, 68(3), 519-533.

Leimu, R., \& Koricheva, J. (2005). Does scientific collaboration increase the impact of ecological articles? Bioscience, 55(5), 438-443.

Levitt, J., \& Thelwall, M. (2009). Citation levels and collaboration within library and information science. Journal of the American Society for Information Science and Technology, 60(3), 434-442.

Levitt, J., \& Thelwall, M. (2010). Does the higher citation of collaborative research differ from region to region? A case study of economics. Scientometrics, 85(1), 171-183.

Leydesdorff, L. \& Felt, U. (2012). Edited volumes, monographs, and book chapters in the Book Citation Index $(\mathrm{BCl})$ and Science Citation Index $(\mathrm{SCl}, \mathrm{SoSCl}, \mathrm{A} \& \mathrm{HCl})$, Journal of Scientometric Research, 1(1), 28-34.

Linmans, A. J. M. (2010). Why with bibliometrics the humanities does not need to be the weakest link: Indicators for research evaluation based on citations, library holdings, and productivity measures. Scientometrics, 83(2), 337-354. doi:10.1007/s11192-009-0088-9

Ma, N., \& Guan, J. C. (2005). An exploratory study on collaboration profiles of Chinese publications in molecular biology. Scientometrics, 65(3), 343-355.

Moody, J. (2004). The structure of a social science collaboration network: Disciplinary cohesion from 1963 to 1999. American Sociological Review, 69, 213-238.

Nederhof, A. (2006). Bibliometric monitoring of research performance in the social sciences and the humanities: A review. Scientometrics, 66(1), 81-100.

Pereira, J. C. R., Fischer, A. L., \& Escuder, M. M. L. (2000). Driving factors of high performance in Brazilian management sciences for the 1981-1995 period. Scientometrics, 49(2), 307-319. 
Persson, O., Glänzel, W., \& Danell, R. (2004). Inflationary bibliometric values: The role of scientific collaboration and the need for relative indicators in evaluative studies. Scientometrics, 60(3), 421-432.

Price, D. J. d. S. (1963). Little science, big science. New York: Columbia University Press.

Sonnenwald, D. H. (2007). Scientific collaboration. In B. Cronin (Ed.), Annual review of information science and technology (41st ed., pp. 643-681). Medford, NJ: Information Today.

Sooryamoorthy, R. (2009). Do types of collaboration change citation? Collaboration and citation patterns of South African science publications. Scientometrics, 81(1), 177-193.

Thompson, J. W. (2007). The death of the scholarly monograph in the humanities? Citation patterns in literary scholarship. Libri. International Journal of Libraries and Information Services, 52(3), 121-131.

Torres-Salinas, D., Robinson-Garcia, N., Cabezas-Clavijo, Á., \& Jiménez-Contreras, E. (2013). Analyzing the citation characteristics of books: Edited books, book series and types of publishers in the book citation index. ArXiv.Org, arXiv:1305.1483. doi:arXiv:1305.1483

Torres-Salinas, D., Rodriguez-Sánchez, R., Robinson-Garcia, N., Fdez-Valdivia, J., \& García, J. A. (2013). Mapping citation patterns of book chapters in the book citation index. Journal of Informetrics, 7(2), 412-424. doi:10.1016/j.joi.2013.01.004

Van Raan, A. F. J. (1998). The influence of international collaboration on the impact of research results. Scientometrics, 42(3), 423-428.

White, H. D., Boell, S. K., Yu, H., Davis, M., Wilson, C. S., \& Cole, F. T. H. (2009). Libcitations: A measure for comparative assessment of book publications in the humanities and social sciences. Journal of the American Society for Information Science and Technology, 60(6), 1083-1096.

Wuchty, S., Jones, B., \& Uzzi, B. (2007). The increasing dominance of teams in production of knowledge. Science, 316, 1036-1038. 